
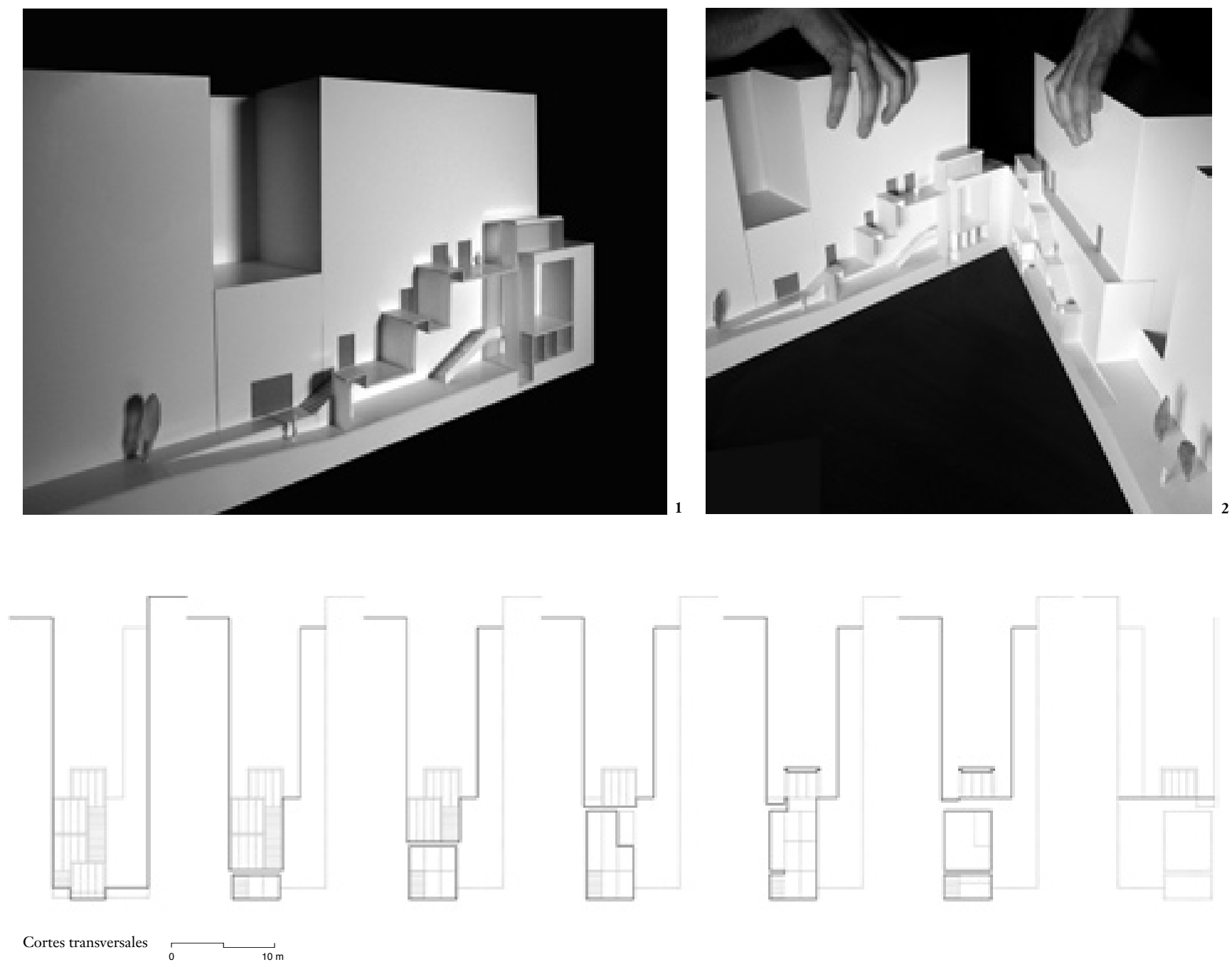

Mansilla + Tuñón arquitectos Madrid, España

\title{
Biblioteca Pública
}

Todas las conexiones de la calle Artistas, que salvan la diferencia de cota entre el antiguo pueblo de Cuatro Caminos y la ciudad voraz y tacaña que, dándole la espalda, lo ha sobrepasado, surgen como cicatrices, heridas mal curadas, apenas unos desalentadores desfiladeros, siempre de paso, entre coches amontonados.

La gran diferencia de cota, casi nueve metros, para tan poco desarrollo y la necesidad de varios accesos a cota intermedia para los edificios vecinos, hacen que el proyecto apueste por un generoso ascensor público, pensando en los cada vez más viejos vecinos del barrio, como enlace de las calles, acompañado por una escalera discreta que admite la aparición de terrazas para los accesos intermedios.

La colocación del elevador público, al fondo, casi en la esquina con la calle Artistas, permite la aparición de una pequeña pero necesaria dotación, que en principio podría ser un centro de día para personas mayores -o quizá una sala de exposiciones o simplemente un lugar donde leer el Quijote-, bajo la escalera y las terrazas, iluminada por cuatro lucernarios -iguales y distintos, como lo son las personas-. Estos lucernarios son la fachada del proyecto y además la barandilla de las terrazas, pero también las lámparas que iluminan por la noche. Un nuevo rostro para las fachadas medianeras y una pequeña plaza arbolada delante, ya sin coches, completan el proyecto.

Los ciudadanos definitivamente debemos ser ambiciosos, y sólo entonces podremos hacer nuestras las palabras de Naguib Mahfuz: “... aunque el callejón está totalmente aislado del bullicio exterior, tiene una vida propia...”. ARQ 


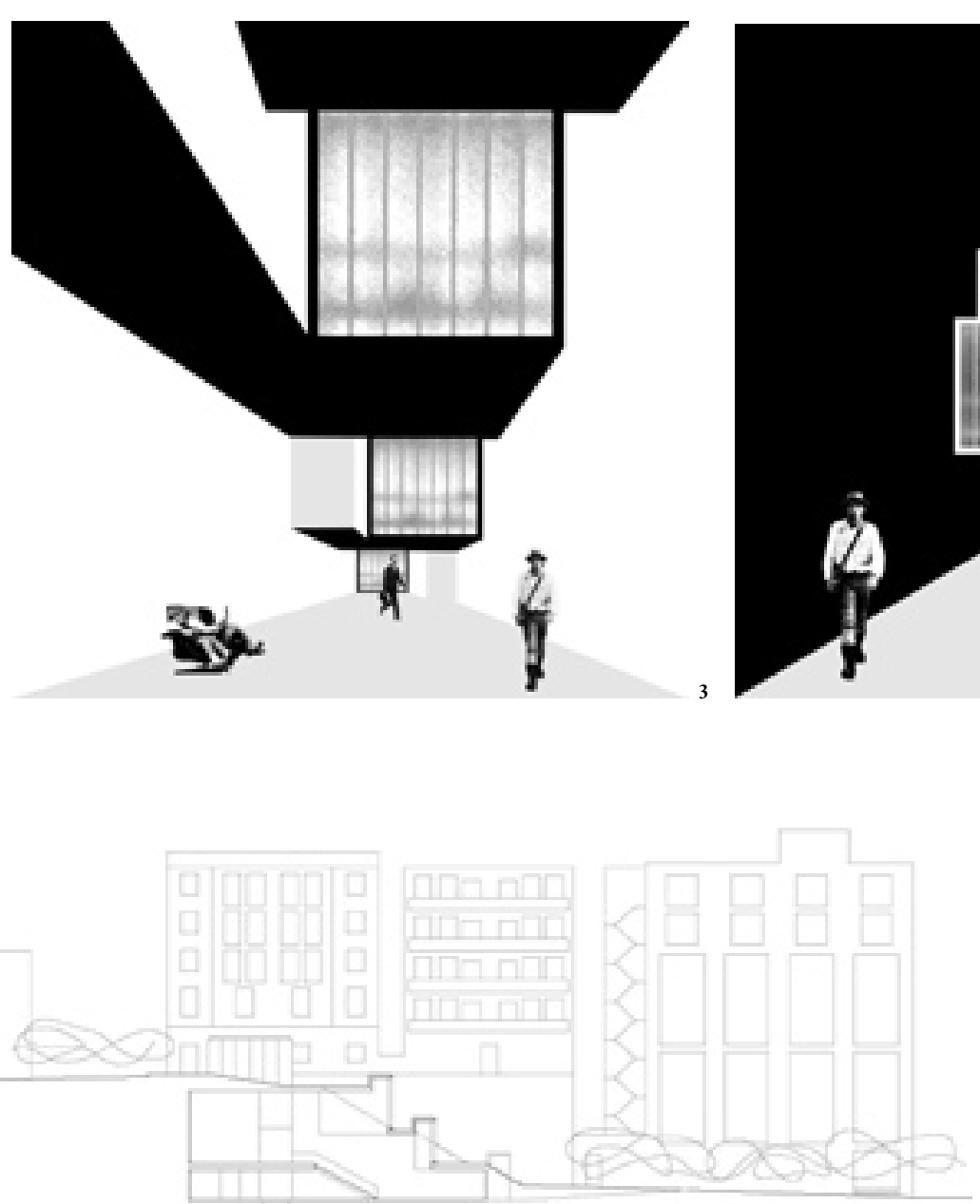

Corte longitudinal AA'

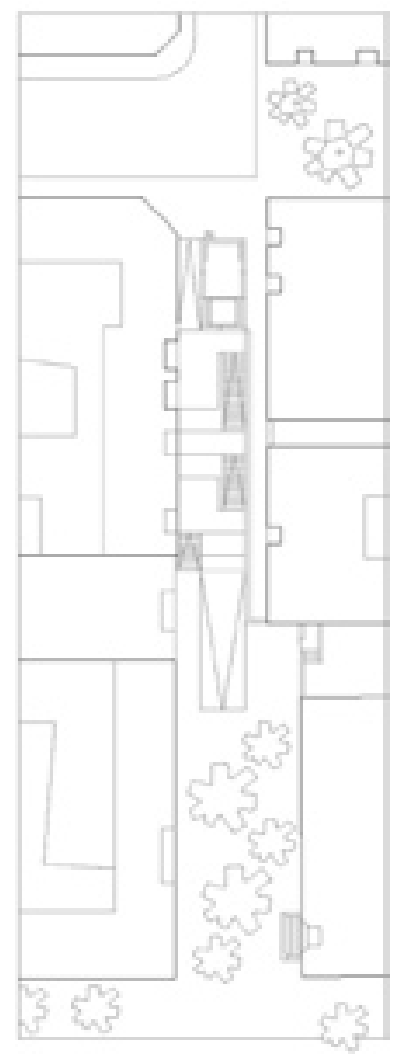

Planta acceso inferior calle Fernández Villaverde

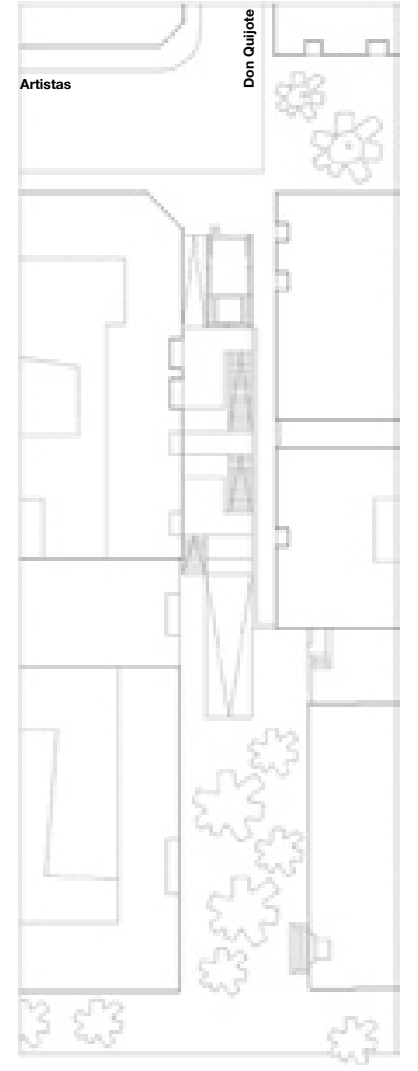

1 Patio de acceso calle
Fernandez Villaverde (nivel +699.0$)$
2 Atención a público (nivel +698.8$)$ 2 Atención a público (nivel +698.8 )

5 Bodega

7 Terraza (nivel +707.8$)$
1 Maqueta proyecto concurso, área poniente; arriba, las calles Artistas y Don Quijote

2 Maqueta del proyecto completo: lucarnas, escaleras y accesos a viviendas existentes

3 Espacio interior propuesto

4 Espacio exterior, calle El Quijote

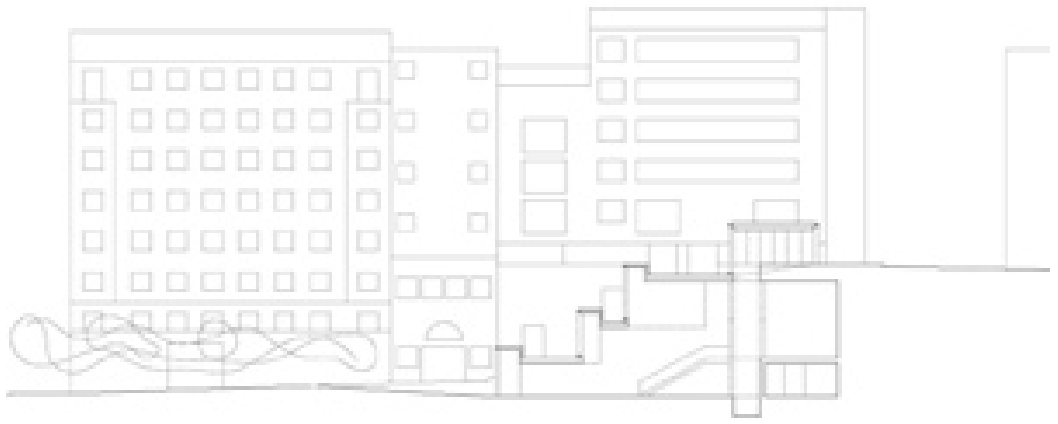

Corte longitudinal BB'

\section{Biblioteca pública}

Arquitectos Luis M. Mansilla, Emilio Tuñón y Luis Díaz-Mauriño Colaboradores Alejandro Valdés, Ainoa Prats y Ricardo Lorenzana

Ubicación Calle Don Quijote entre Artistas y Fernández Villaverde, Madrid, España

Cliente Empresa Municipal de la Vivienda de Madrid Materialidad Hormisón armado visto, perfiles de vidrio estructurales

Presupuesto de la obra No asiznado

Superficie proyecto $143 \mathrm{~m}^{2}$

Año proyecto 2003 (concurso)

Fotografía Alejandro Valdés

Imásenes digitales Alejandro Valdés 